\title{
The effect of fasting on enzyme levels in the enlarged and involuting rat pancreas
}

\author{
BY R. A. CRASS ${ }^{1}$, P. S. OATES ${ }^{2}$ AND R. G. H. MORGAN ${ }^{1}$ \\ ${ }^{1}$ Department of Physiology, University of Western Australia, Nedlands, Western \\ Australia, 6009, Australia and ${ }^{2}$ Department of Human Biology, Curtin University of \\ Technology, Bentley, Western Australia, 6109, Australia
}

(Received 5 January 1987 - Accepted 28 May 1987)

1. The effect on pancreatic digestive enzyme levels of fasting and changes from a diet containing trypsin inhibitor (raw soya-bean flour, RSF) to diets free of trypsin inhibitor (heated soya-bean flour, HSF, or commercial rat chow) was studied in rats for up to $7 \mathrm{~d}$.

2. In RSF-fed rats killed without fasting, enzyme levels were low, but after fasting for $24 \mathrm{~h}$ before killing therc was a marked increase in all enzyme levels. Histological studies showed that pancreatic acinar cells from RSF-fed rats killed without fasting were devoid of zymogen granules, but following a $24 \mathrm{~h}$ fast there was a marked accumulation of zymogen granules which extend into the basal cytoplasm. Fasting either produced no change or a fall in enzyme levels in rats fasted after feeding HSF or chow continuously.

3. If animals fed on RSF were changed to HSF and either fed or fasted for $24 \mathrm{~h}$ up to the time of killing there was an increase in amylase (EC 3.2.1.1), trypsin (EC 3.4.21.4), lipase (triacylglycerol lipase; $E C$ 3.1.1.3) and protein $1 \mathrm{~d}$ after the change, followed by a fall over the next $6 \mathrm{~d}$ to levels similar to those seen in rats fed on HSF continuously.

4. Animals changed from RSF to chow showed similar effects as far as trypsin, lipase and protein were concerned, but amylase rose, to reach the level seen in rats fed on chow continuously (about ten times that seen in soya-bean-fed rats), after $2 \mathrm{~d}$.

5. These results suggest that in the rats fed on RSF, pancreatic enzyme synthesis is rapid but secretion is equally rapid and intracellular enzyme levels are low. When these animals are fasted or changed to a diet free of trypsin inhibitor the rate of secretion falls but the high rate of synthesis continues for at least $24 \mathrm{~h}$ and enzymes accumulate in the pancreas. In studies of pancreatic enzyme levels in rats fed on trypsin inhibitor the extent of fasting before killing the animal is therefore an important variable. Such animals should probably not be fasted before study.

When rats are fed on raw soya-bean flour (RSF) for prolonged periods, marked pancreatic enlargement occurs as a result of a mixture of acinar cell hypertrophy and hyperplasia (Crass \& Morgan, 1982; Oates \& Morgan, 1982). This growth is thought to be due largely to the presence of a potent, heat labile trypsin inhibitor present in the diet. When the diet is changed to one free of inhibitor after up to 26 weeks of feeding with RSF, rapid reversal of the pancreatic enlargement is seen (Crass \& Mogan, 1981; Oates et al. 1986). The pancreatic growth and regression is probably due to changes in the plasma levels of cholecystokinin (CCK), a trophic hormone for the pancreas (Petersen $e t$ al. 1978; Solomon et al. 1978; Morisset, 1980; Oates \& Morgan, 1984a). In the rat CCK release appears to be suppressed by the presence of free trypsin in the gut lumen (Green \& Lyman, 1972), however, due to the presence of the trypsin inhibitor in the RSF diet, it is thought that when this diet is given free trypsin levels in the gut fall (Morgan, 1987), and the suppression of CCK release no longer occurs. CCK levels in the blood therefore rise (Louie et al. 1986), and pancreatic enlargement and increased pancreatic secretion occur until the levels of free trypsin in the gut lumen are restored to those seen in rats fed on a normal diet (Morgan, 1987). When the trypsin inhibitor is removed from the diet high levels of free trypsin in the gut lumen suppress CCK release, and pancreatic involution occurs by the process of apoptosis (Oates et al. 1986)

In many studies the effect of trypsin inhibitor feeding has been followed by measurement 
of pancreatic enzyme levels. Most such studies have found that proteolytic enzyme levels are raised in the enlarged pancreas (Arnesjö et al. 1973; Fölsch et al. 1974; Naim et al. 1982; Temler et al. 1984), but falls have also been reported (Haines \& Lyman, 1961; Abbey et al. 1979). Studies by Nitsan \& Liener (1976) showed that in rats fed on trypsin inhibitor, pancreatic enzyme levels were different in fasted and fed animals. In the studies listed above, fasted animals were used in the studies showing increased enzyme levels, while in the studies showing a decrease the animals were killed without fasting. According to the previously described model, if the animals were fasted following feeding with RSF the levels of trypsin inhibitor in the gut would fall, lumen free trypsin levels would rise and suppress CCK release, and thus plasma CCK levels would fall. The effect of fasting would thus be similar to a change to a diet free of trypsin inhibitor. Whether this loss of pancreatic stimulation would result in an increase or a decrease in pancreatic enzyme levels would depend on how rapidly the fall in CCK levels affect the opposing processes of synthesis and secretion of enzymes.

The present paper reports the effect of fasting on pancreatic tissue enzyme levels in the enlarged pancreas caused by a RSF diet and in the involuting pancreas after a change to a chow or heated soya-bean flour (HSF) diet. The results suggest that in the pancreas of the rat fed on RSF both enzyme synthesis and enzyme secretion are markedly stimulated, with little intracellular accumulation of enzymes. When these animals are fasted, pancreatic enzyme secretion immediately falls, but rapid enzyme synthesis continues, with the accumulation of zymogen granules. Changing animals fed on RSF to diets of trypsin inhibitor has a similar effect.

\section{MATERIALS AND METHODS}

Diets

Rat chow was supplied by W. H. Milne \& Co. Pty Ltd, Welshpool, Western Australia. RSF and HSF were supplied by Soy Products of Australia Pty Ltd, Bayswater, Victoria, and supplemented with vitamins and minerals as recommended by Fölsch \& Wormsley (1974). The suppliers stated that the HSF was prepared by steam-heating RSF under pressure at $120^{\circ}$ for $20-35 \mathrm{~min}$ followed by gradually drying back to $40-60 \mathrm{mg}$ moisture/g in order to destroy most of the trypsin inhibitor in the flour. Assay for trypsin inhibitor content by the method of Kakade et al. (1974) showed insignificant inhibition of trypsin by $1 \mathrm{~g}$ chow diet or HSF, while approximately $40 \mathrm{mg}$ trypsin was inhibited by $1 \mathrm{~g}$ RSF. The soya-beanflour diets contained $(\mathrm{g} / \mathrm{kg}) 200 \mathrm{fat}, 400$ protein and 250 carbohydrate, while the chow contained $(\mathrm{g} / \mathrm{kg}) 50$ fat, 220 protein and 520 carbohydrate.

\section{Animals}

Seventy-seven male albino rats originally derived from a Wistar strain, locally inbred for 27 years, between 12 and 16 weeks old, were used for the four groups studied. The animals were held in wire-mesh-bottom cages and maintained in lighted conditions from 05.00 to 18.00 hours daily. Fasted rats were fasted from 09.00 hours for $22-24 \mathrm{~h}$, with free access to water. Unfasted rats were allowed access to food and water up to the time they were killed.

\section{Experimental design}

Sixty-one rats (average weight $210 \mathrm{~g}$ at the time of killing) were fed on RSF for 4 weeks to produce maximal pancreatic enlargement (Oates \& Morgan, 1982). After 4 weeks of feeding on RSF, sixteen of these rats were killed to provide baseline values ( 0 time), eight fasted and eight unfasted. The remaining rats were changed to the following two diets. 
Group 1, RSF changed to chow. Twenty-one rats were changed to a chow diet. Four fasted and four unfasted rats were killed after 1 and $2 \mathrm{~d}$ on the chow diet. Two fasted and three unfasted animals were killed after $7 \mathrm{~d}$ on the chow diet.

Group 2, RSF changed to HSF. The remaining twenty four rats were changed to a diet of HSF. Eight animals, four fasted and four unfasted, were killed 1, 2 and $7 \mathrm{~d}$ after changing to HSF.

Chow fed. Eight rats (average weight $240 \mathrm{~g}$ ), chow fed from the time of weaning were killed to provide control values for group 1. Four were killed after fasting and four killed unfasted.

HSF fed. Eight rats (average weight $193 \mathrm{~g}$ ) were fed on a diet of HSF for 4 weeks to provide control values for group 2. Four rats were killed after fasting and four unfasted.

\section{Removal of pancreas}

All animals were anaesthetized with diethyl ether, a mid-line incision made, the heart incised to kill the animal and the pancreas rapidly removed. The excised pancreas was trimmed of fat and lymph tissue, weighed, flattened between Parafilm (American Can Company, Greenwich, Conn.) and frozen on dry ice for measurement of enzymes later on the same day.

\section{Tissue extraction}

Approximately $1 \mathrm{~h}$ after removal, the frozen pancreas was finely minced with a razor blade and homogenized in a Teflon-in-glass round-bottom homogenizer (10 strokes, 4000 rev./ min.) in $25 \mathrm{ml}$ chilled distilled water. This homogenate was used for the assay of trypsin. A portion of the homogenate was also diluted $1: 10$ in chilled water and sonicated in a Branson Sonifier (Model B30; Branson Sonic Power Co., Danbury, Conn.) at a setting of 5 for $30 \mathrm{~s}$. Portions of this pancreatic sonicate were used for the assay of amylase, lipase and total protein.

\section{Enzyme assays}

Trypsin (EC3.4.21.4). Trypsin activity was assayed by the method of Preiser et al. (1975) using benzoyl-DL-arginine-p-nitroanilide (BAPNA) as substrate. Trypsinogen in the homogenate was activated with porcine enterokinase (enteropeptidase: EC 3.4.21.9, Miles Laboratories, Goodwood, South Africa) at a concentration of $8 \mathrm{mg} / \mathrm{ml} \mathrm{in} 0.05 \mathrm{M}$ Tris buffer, $\mathrm{pH} \mathrm{7.9.} \mathrm{A} 100 \mu \mathrm{l}$ portion of pancreatic homogenate plus $300 \mu \mathrm{l}$ distilled water was incubated with $20 \mu \mathrm{l}$ enterokinase for $45 \mathrm{~min}$ at $30^{\circ}$. These conditions yielded maximal activation of trypsinogen to trypsin (Crass, 1983). At exactly $45 \mathrm{~min} 2.8 \mathrm{ml}$ BAPNA were added and the sample incubated for a further $5 \mathrm{~min}$. The hydrolysis reaction was then terminated by the addition of $3.2 \mathrm{ml}$ acetic acid $(300 \mathrm{~g} / \mathrm{l})$. To correct for variable turbidity a blank assay was performed for each sample using a duplicate portion of the homogenate. The blank was assayed under the same conditions as the sample except that after the 45 min activation period acetic acid $(300 \mathrm{~g} / 1)$ was added to inactivate the reaction before the addition of BAPNA. Trypsin activity was determined from the nitroaniline concentrations as measured by the difference in the optical density at $410 \mathrm{~nm}$ between the sample and the corresponding blank. Trypsin activity is expressed as units (U), one unit being defined as the amount of enzyme which releases $1 \mu \mathrm{mol} p$-nitroaniline from BAPNA per min under the conditions described previously.

$\alpha$-Amylase (EC 3.2.1.1). $\alpha$-Amylase activity was determined by the method of Dahlquist (1962). 
Lipase (triacylglycerol lipase; EC 3.1.1.3). Lipase activity was assayed at $25^{\circ}$ by the turbidimetric method of Shihabi \& Bishop (1971) as modified by Verduin et al. (1973).

Protein. Total tissue protein was assayed by the method of Schacterle \& Pollack (1973).

\section{Histology}

In a separate group of rats pancreatic tissue was taken for histology after feeding RSF for 4 weeks before and after fasting for $6,12,18$ and $24 \mathrm{~h}$, and in rats changed to HSF or chow for 1 and $2 \mathrm{~d}$. The animals were treated in the same way as animals used in the biochemical studies. Following death a 100-200 mg segment of the splenic region of the pancreas was removed and cut into $1 \mathrm{~mm}$ cubes while immersed in glutaraldehyde $(25 \mathrm{~g} / 1$; TAAB Laboratories, Reading, Berks) in $0.1 \mathrm{M}$-cacodylate buffer, pH 7.4 (BDH Chemicals, Poole, Dorset). The specimens were then transferred to fresh fixative and rotated for at least $6 \mathrm{~h}$ to maximise penetration of the fixative. The fixed tissue was then postfixed in osmium

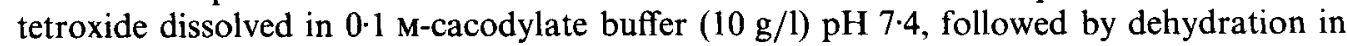
ethanol and embedding in Araldite (Probing \& Structure, Aitkenvale, Queensiand). Sections were cut using an LKB ultramicrotome. Sections for light miocroscopy were stained with toluidine blue and sections used in electron microscopy were stained with lead citrate.

\section{Statistical analysis}

Results are expressed as means with their standard errors. Values for fed and fasted animals for various times after changing the diet were analysed by two-way analysis of variance. Significance was considered to be $P<0.05$.

\section{RESULTS}

It should be noted that in the following discussion fasted animals described as having been fed on chow or HSF for 1,23 and $8 \mathrm{~d}$ had been fasted $24 \mathrm{~h}$ before killing, so that the $1 \mathrm{~d}$ value shows the effects of fasting for $24 \mathrm{~h}$ rats which had previously been fed on RSF. The 2, 3 and $8 \mathrm{~d}$ values represent the effects of feeding inhibitor-free diets for 1,2 and $7 \mathrm{~d}$ respectively.

\section{Effect of fasting on pancreatic enzyme content (Fig. 1 and Plate 1)}

When rats fed on RSF were fasted for $24 \mathrm{~h}$ before killing, there was a significant increase in total pancreatic amylase, trypsin, lipase and total protein compared with rats not fasted. Pancreatic weight also increased. In contrast, in chow-fed and HSF-fed control rats, fasting either did not significantly alter or produced a fall in the measured variables compared with their respective fed conditions (Fig. 1 and Plate 1).

The results of the histological studies supported the biochemical values (Plate $1 a-d$ ). They showed a distinct difference between rats fed on RSF and those fasted from 6 to $24 \mathrm{~h}$ before killing. In animals fed on RSF up to the time of killing, the acinar cells were devoid of mature zymogen granules. The lumen of the acinus contained a material of staining density similar to that seen in the secretory granules, suggesting increased discharge. In marked contrast however, as early as $6 \mathrm{~h}$ after fasting there was a significant accumulation of zymogen granules which extended into the basal cytoplasm. The pancreatic acinar lumen was relatively free of electron-dense material, suggesting decreased protein discharge. In control animals fed on HSF or chow, fasting for up to $24 \mathrm{~h}$ did not produce any obvious morphological changes in the acinar cell or the acinus lumen. 


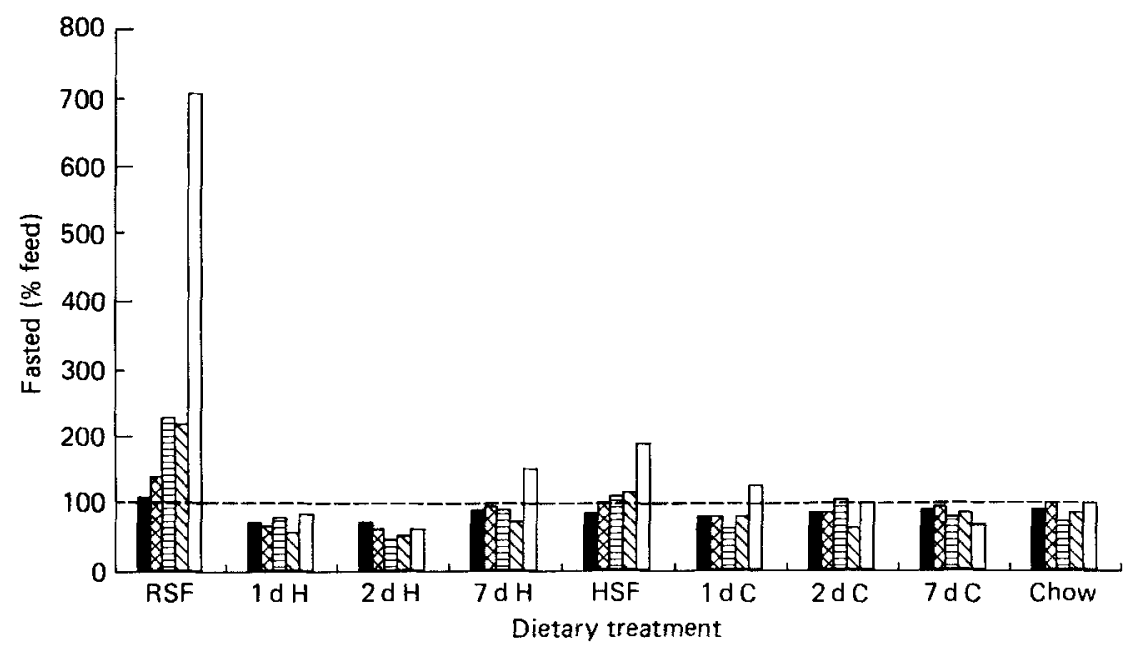

Fig. 1. Pancreatic weight, protein and enzymes in animals fasted for $24 \mathrm{~h}$ before killing, expressed as a percentage of the corresponding values in animals killed without fasting, after various diets. RSF, raw soya-bean flour; HSF, heated soya-bean flour; Chow, standard rat chow; $1 \mathrm{~d} \mathrm{H}, 2 \mathrm{~d} \mathrm{H}, 7 \mathrm{~d} \mathrm{H}, 1,2$ and $7 \mathrm{~d}$ after change from RSF to HSF; $1 \mathrm{~d} \mathrm{C}, 2 \mathrm{~d} \mathrm{C}, 7 \mathrm{~d} \mathrm{C}, 1,2$ and $7 \mathrm{~d}$ after change from RSF to chow. ( $)$ ), Weight; (因), protein; (国), trypsin (EC 3.4.21.4); $($ ), lipase (triacylglycerol lipase; EC 3.1.1.3); (口), amylase (EC 3.2.1.I).
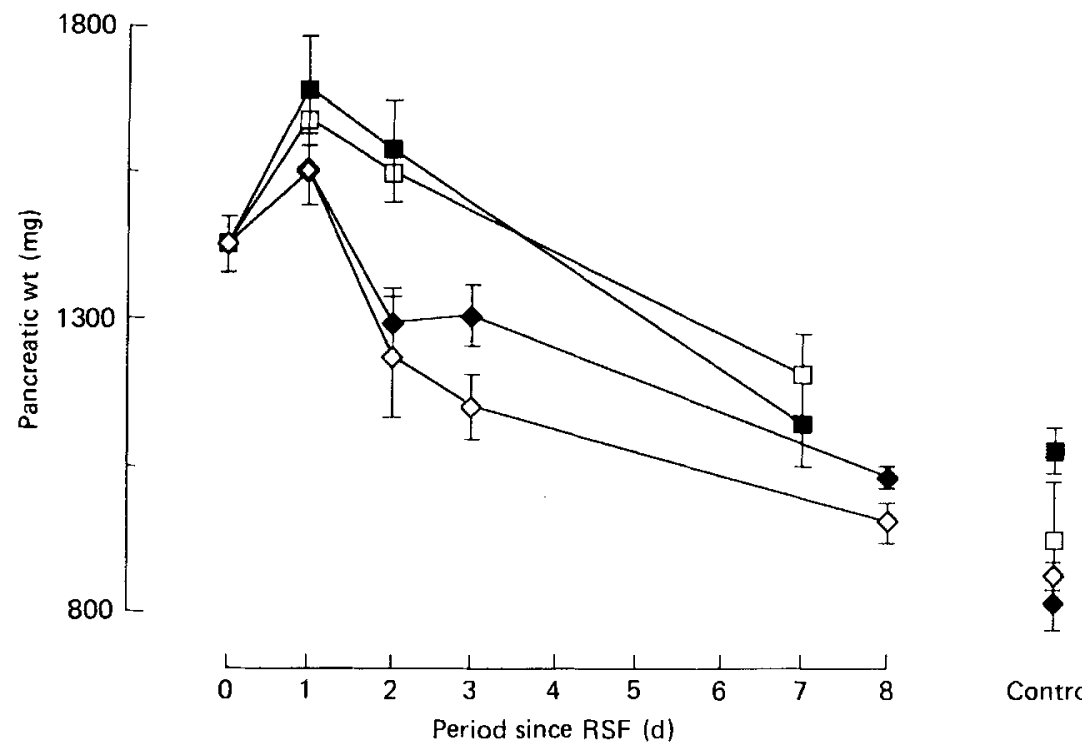

Control

Fig. 2. Pancreatic weight in rats fed on raw soya bean-flour (RSF) for 4 weeks and then given chow or heated soya bean-flour (HSF). 'Fed' animals were killed without fasting after 1, 2 or $7 \mathrm{~d}$ on the diets. 'Fasted' animals were fasted for $24 \mathrm{~h}$ before killing in addition to $0,1,2$, and $7 \mathrm{~d}$ on the diets. The points for fasted animals at $\mathrm{I} d$ since RSF feeding, therefore indicate values for eight rats fed on RSF and then fasted for $24 \mathrm{~h}$ before killing. ( $\square$ ), Chow fed; $(\diamond)$, chow fasted; $(\square)$, HSF fed; $(\diamond)$, HSF fasted; control, chow from weaning or HSF for 4 weeks before study. Points are means with their standard errors represented by vertical bars. 

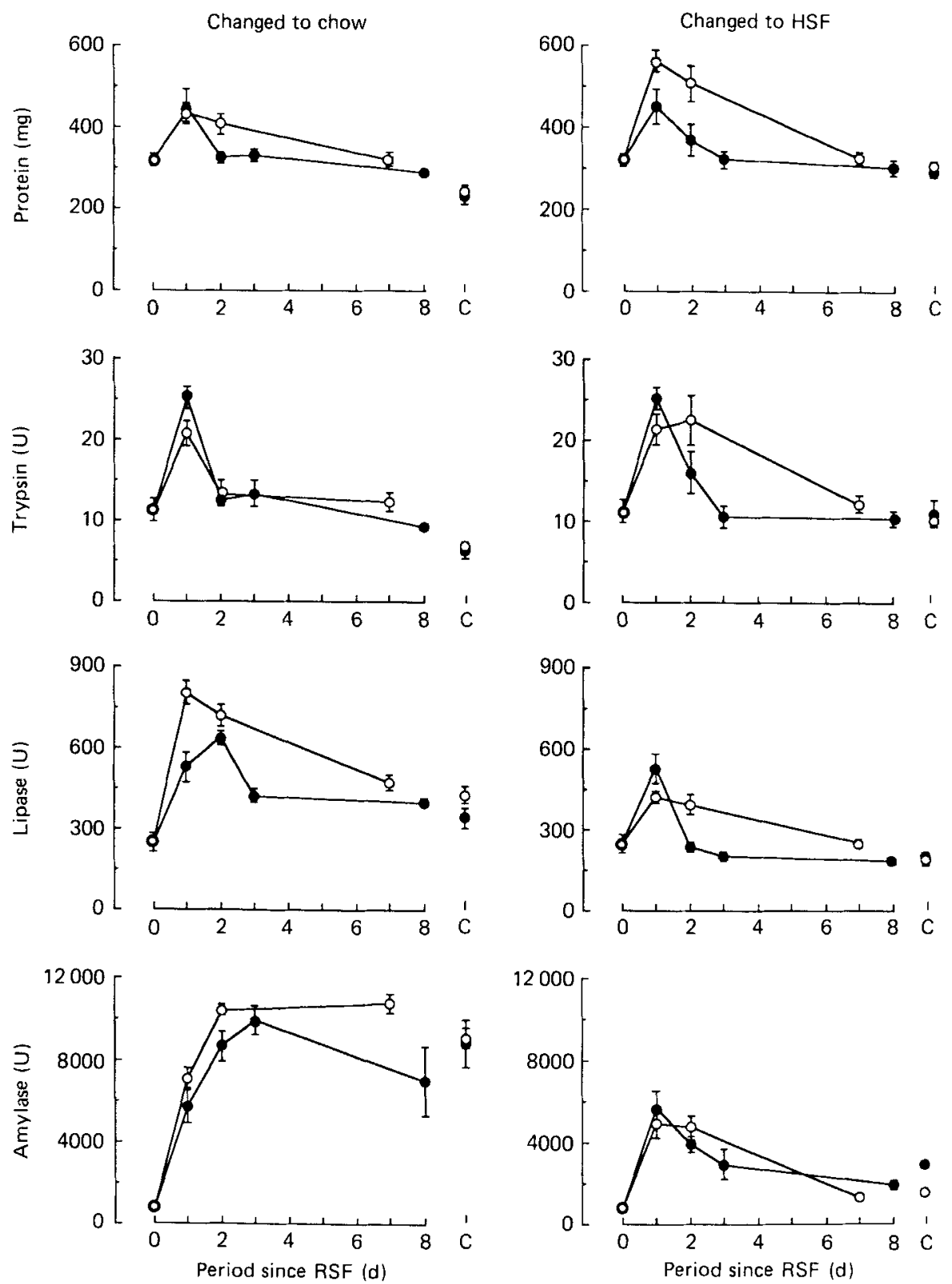

Fig. 3. Total pancreatic protein, trypsin (EC 3.4.21 .4), lipase (triacylglycerol lipase; EC 3.1 1.3) and amylase $(E C 3.2 .1 .1)$ in rats fed on raw soya-bean flour (RSF) for 4 weeks and then given chow or heated soya-bean flour (HSF). 'Fed' animals $(O)$ were killed without fasting after 1,2 or $7 \mathrm{~d}$ on the diets. 'Fasted' animals (O) were fasted for $24 \mathrm{~h}$ before killing, in addtion to $0, \mathrm{I}, 2$, and $7 \mathrm{~d}$ on the diets. The points for fasted animals at $1 \mathrm{~d}$ since RSF feeding, therefore indicate values for eight rats fed on RSF and then fasted for $24 \mathrm{~h}$ before killing. C, control animals, fed on rat chow continuously from weaning (approximately 8 weeks) or HSF for 4 weeks. Points are means with their standard errors represented by vertical bars. 


\section{Effects of diet on pancreatic weight (Fig. 2)}

In rats fed on RSF, pancreatic weight was significantly greater than that of the control rats fed on either chow or HSF. When the diet was changed from RSF to one free of trypsin inhibitor, and the animals killed without fasting, pancreatic weight increased after $1 \mathrm{~d}$, but then fell gradually and by $7 \mathrm{~d}$ was not significantly different from the weight seen in rats fed on HSF for 4 weeks or chow from weaning.

A similar pattern was seen in fasted rats following the change from the RSF diet; however, in this group the rate of involution, as assessed by the fall in pancreatic weight, was significantly greater compared with unfasted animals.

\section{Effect of changes in diet on enzyme content (Fig. 3)}

Group 1:RSF to chow. If the animals were killed without fasting, pancreatic protein, trypsin and lipase were similar, but amylase levels were greatly depressed in rats fed on RSF compared with chow-fed controls. However, if the animals were changed to chow for $24 \mathrm{~h}$, the levels of protein, trypsin and lipase markedly increased, leading to significantly higher levels of these proteins, compared with the group fed on RSF and the chow-fed control animals.

By $48 \mathrm{~h}$ after the change to chow, in both fasted and unfasted rats, the levels of protein, trypsin and lipase returned to those of chow-fed controls and these levels were maintained for the remainder of the study. The rise in amylase seen after the 1st day on chow brought the values up to those seen in control animals and these levels were maintained for the remainder of the study period.

Group 2: RSF to HSF (Fig. 3). The patterns of change seen when the diet was altered from RSF to HSF, in both fasted and unfasted rats, were fundamentally similar to those seen after the change from RSF to chow. The effects on amylase were, however, different. In animals changed from RSF to HSF, amylase initially increased and then fell towards control values, but the increase was less than that seen in animals changed from RSF to chow, and at all time periods studied both enzymes were significantly lower in rats fed on HSF than in rats fed on chow.

Histological studies indicated that despite the fed state, animals changed from RSF to diets of chow or HSF for $24 \mathrm{~h}$ showed a marked accumulation of zymogen granules which extended into the basal cytoplasm of the pancreatic acinar cell. This appearance was similar to that seen in rats fed on RSF and fasted for $24 \mathrm{~h}$ (Plate $1 c, d$ ).

\section{DISCUSSION}

The present studies show that whether the animal is fasted or fed before killing is a major variable in studies of pancreatic enzyme content in rats fed on trypsin inhibitor. It is probably of considerably less importance in animals fed on diets free of trypsin inhibitor. Thus, after feeding RSF for 4 weeks, pancreatic enzyme levels were low and few zymogen granules were present in the acinar cells. The low enzyme levels in the pancreas of these animals could probably be inferred from the previous finding that very few zymogen granules are present in the pancreas of animals fed on RSF for even short periods (Oates \& Morgan, 1984b). These histological findings were confirmed in the present study. Fasting these animals for $24 \mathrm{~h}$ caused a marked increase in enzyme content and zymogen granules accumulated in the acinar cells. In contrast, in animals fed on HSF for 4 weeks or chow from weaning, fasting for $24 \mathrm{~h}$ had little effect on pancreatic enzyme levels. Pancreatic enzyme levels and zymogen granule content also increased markedly after the change to an inhibitor-free diet in unfasted animals for $24 \mathrm{~h}$. 
For the present biochemical studies a fast of 22-24 h was used. This period was chosen because preliminary studies showed considerable food still present in the stomach of some animals after $12 \mathrm{~h}$ fasting and measurements of pancreatic enzyme levels at this time were variable. However, judging from the histological appearance of a rapid accumulation of zymogen granules in the pancreas of RSF-fed rats fasted for as little as $6 \mathrm{~h}$, it seems likely that in rats previously fed on trypsin inhibitor, fasting for even short periods would result in considerable changes in pancreatic enzyme levels. Nitsan \& Liener (1976) also used a $24 \mathrm{~h}$ fast. Their results were qualitatively similar to those of the present study but differences between fed and fasted rats were less marked. This probably reflects differences in the composition of the diets.

The most reasonable interpretation of these results is that in the animals fed on RSF, pancreatic enzyme synthesis and enzyme discharge are both strongly stimulated by CCK and enzyme accumulation does not occur because the rate of secretion is potentially more rapid than the rate of synthesis. Following the removal of the lumen stimulation for CCK release, by fasting overnight or by changing the diet to one free of trypsin inhibitor, plasma levels of CCK would rapidly fall. When this happens secretion apparently falls immediately but the rapid synthesis rate continuous for some time and enzymes accumulate in the pancreas. This was confirmed histologically. The increased pancreatic weight observed after a change to the inhibitor-free diets for $24 \mathrm{~h}$ or in RSF-fed rats fasted for $24 \mathrm{~h}$ (Fig. 2) probably results from an imbalance between protein synthesis and discharge at this time, resulting in the accumulation of enzymes. However, by $7 \mathrm{~d}$ on the inhibitor-free diets, synthesis had apparently returned to normal, since weight and enzyme levels had returned to the respective control values. It is interesting to note that the rate of pancreatic involution after the change to an inhibitor-free diet was greater in fasted compared with unfasted animals. The different responses probably reflect different levels of CCK in the circulation after the change from RSF. After fasting for $24 \mathrm{~h}$, the levels of dietary protein in the gut lumen is likely to be minimal, resulting in maximal suppression of CCK release by free trypsin. However, when a diet containing protein (HSF or chow) is fed, protein in the gut lumen will bind free trypsin and the suppression of CCK release will be less marked. Under these circumstances it would be expected that the relatively high levels of CCK in fed animals would reduce the rate of involution compared with fasted rats.

Pancreatic enzyme levels in rats fed on a diet containing trypsin inhibitor and fasted overnight before killing have been reported by a number of other workers (Arnesjö et al. 1973; Fölsch et al. 1974; Naim et al. 1982; Temler et al. 1984). Konijn et al. (1970) also studied the enzyme content of rats fed on RSF compared with rats fed on HSF in the fed and fasted states. However, although they found effects on trypsin levels similar to those presented here, the effect of fasting on amylase levels was different. In particular, in fasted rats fed on diets containing RSF the pancreas contained less amylase than that in fasted rats fed on diets containing HSF. This is in marked contrast to the present study in which the pancreas from fasted rats previously fed on RSF contained over four times as much amylase as the pancreas from fasted rats fed on HSF (5727 (SEM 602) U v. 1335 (SEM 154) $\mathrm{U}$ ). In a later extension of their study, Konijn et al. (1972) examined the effect of fasting and feeding on the enzyme content of rats fed on either RSF or HSF for 3 months. They found in this later study that the pancreas of fasted rats fed on RSF contained less amylase than the pancreas of fed RSF-fed rats and fasted HSF-fed rats, again in contrast to the present study. The reason for the differences between the studies reported by Konijn's group (Konijn et al. 1970, 1972) and the present study is not known. Factors which might contribute include the use by Konijn et al. $(1970,1972)$ of younger rats $(40-50 \mathrm{~g}$ at the start of the study $v .200 \mathrm{~g}$ rats used in the present study), the use of a shorter fasting period (16 v. $22 \mathrm{~h}$ ) and different dietary composition. However, none of these differences appear to be sufficiently important to account for the fundamental differences seen. 
The relative levels of the different pancreatic enzymes in chow-fed control rats were different from those in RSF- or HSF-fed rats, with higher amylase levels and lower trypsin levels in rats fed on chow than in rats fed on the other diets. This almost certainly reflects the different composition of these diets, chow being richer in carbohydrates and poorer in protein and fat than RSF or HSF. It is not surprizing, therefore that when the diet was changed from RSF to chow a substantial change in enzyme composition was found and the response differed from that seen when RSF was changed to HSF. Fölsch et al. (1974) showed a similar change in the enzyme composition of the pancreas of rats fed on HSF compared with rats fed on a standard chow diet, with less amylase and more trypsin and lipase content in HSF-fed rats compared with rats fed on chow. These workers also postulated that the changes in enzyme composition between HSF and chow-fed rats was related to diet composition.

The present studies indicate that in investigations of animals fed on RSF, fasting can rapidly alter the pancreatic enzyme levels. Such animals should probably be studied unfasted, but, if fasting is used, the extent of this must be precisely defined to allow effective evaluation of the results.

This work was supported by grants from the National Health \& Medical Research Council of Australia and The Cancer Council of Western Australia.

\section{REFERENCES}

Abbey, B. W., Norton, G. \& Neale, R. J. (1979). British Journal of Nutrition 41, 39-45.

Arnesjö, B., Ihse, I., Lundquist, I. \& Quist, I. (1973). Scandanavian Journal of Gastroenterology 8, 545-554.

Crass, R. A. (1983). The effects of soya flour diets and azaserine on the growth and function of the rat pancreas. PhD Thesis, University of Western Australia.

Crass, R. A. \& Morgan, R. G. H. (1981). International Journal of Vitamin and Nutrition Research 51, 85-91.

Crass, R. A. \& Morgan, R. G. H. (1982). British Journal of Nutrition 47, 119-129.

Dahlquist, A. (1962). Scandanavian Journal of Clinical and Laboratory Investigation 14, 145-151.

Fölsch, U. R., Winckler, K. \& Wormsley, K. G. (1974). Digestion 11, 161-171.

Fölsch, U. R. \& Wormsley, K. G. (1974). Scandanavian Journal of Gastroenterology 9, 679-683.

Green, G. M. \& Lyman, R. L. (1972). Proceedings of the Society for Experimental Biology and Medicine 140, 6-12.

Haines, P. C. \& Lyman, R. (1961). Journal of Nutrition 74, 445-452.

Kakade, M. L., Rackis, J. J., McGhee, J. E. \& Puski, G. (1974) Cereal Chemistry 51 376-382.

Konijn, A. M., Birk, Y. \& Guggenheim, K. (1970). Journal of Nutrition 100, 361-368.

Konijn, A. M., Eyal, Z., Birnbaum, D. \& Guggenheim, K. (1972). Digestion 6, 330-337.

Louie, D. S., May, D., Miller, P. \& Owyang, C. (1986). American Journal of Physiology 250, G252-G259.

Morgan, R. G. H. (1987). Gut (In the Press).

Morisset, J. (1980). Biomedical Research 1, 405409.

Naim, M., Gertler, A. \& Birk, Y, (1982), British Journal of Nutrition 47, $281-288$.

Nitsan, Z. \& Liener, I. E. (1976). Journal of Nutrition 106, 300-305.

Oates, P. S. \& Morgan, R. G. H. (1982). American Journal of Pathology 108, 217-224.

Oates, P. S. \& Morgan, R. G. H. (1984a). American Journal of Physiology 247, G457-G462.

Oates, P. S. \& Morgan, R. G. H. (1984b). American Journal of Physiology 247, G667-G673.

Oates, P. S., Morgan, R. G. H. \& Light, A. M. (1986). American Journal of Physiology 250, G9-G14.

Petersen, H., Solomon, T. \& Grossman, M. I. (1978). American Journal of Physiology 234, E286-E293.

Preiser, H., Schmilz, J., Maestracci, D. \& Crane, R. K. (1975). Clinica Chimica Acta 59, 169-175.

Schacterle, G. R. \& Pollack, R. L. (1973). Analytical Biochemistry 51, 654-655.

Shihabi, Z. K. \& Bishop, C. (1971). Clinical Chemistry 17, 1150-1153.

Solomon, T. E., Petersen, H., Elashoff, J. \& Grossman, M. I. (1978). American Journal of Physiology 235, E714-E719.

Temler, R. S., Dormond, C. A. Simon, E., Morel, B. \& Mettraux, C. (1984). Journal of Nutrition 114, 270-278.

Verduin, P. A., Punt, J. M. H. M. \& Kreutzer, H. H. (1973). Clinica Chimica Acta 46, 11-19. 


\section{EXPLANATION OF PLATE}

Plate 1. (a) Light micrograph of pancreatic acinar cells during raw soya-bean flour (RSF) feeding in unfasted animals. The cells are devoid of mature zymogen granules. (b) Electron micrograph of pancreatic tissue in rats fed on RSF up to the time of killing. It shows the presence of smaller secretory granules. The duct lumen (L) contains a material of similar staining characteristics to the secretory granules. (D), lipid droplets. (c) Light micrograph of pancreatic acinar tissue after $24 \mathrm{~h}$ fasting in rats previously fed on RSF. Note the marked accumulation of zymogen granules which extend into the basal cytoplasm. (d) Electron micrograph demonstrating the large accumulation of zymogen granules in rats fed on RSF and fasted for $24 \mathrm{~h}$. In addition the acinus lumen is clear of any electron-dense staining material. 

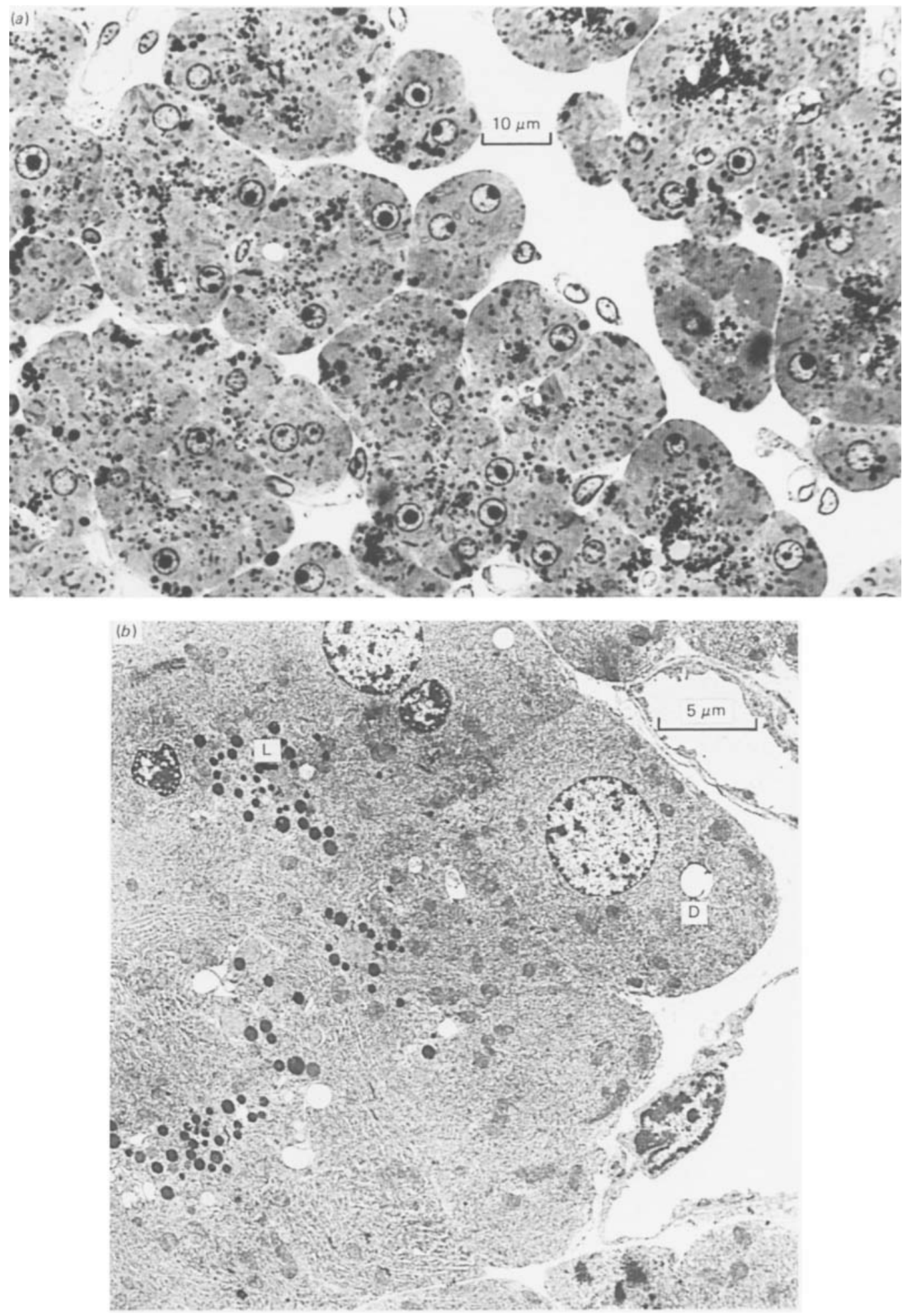

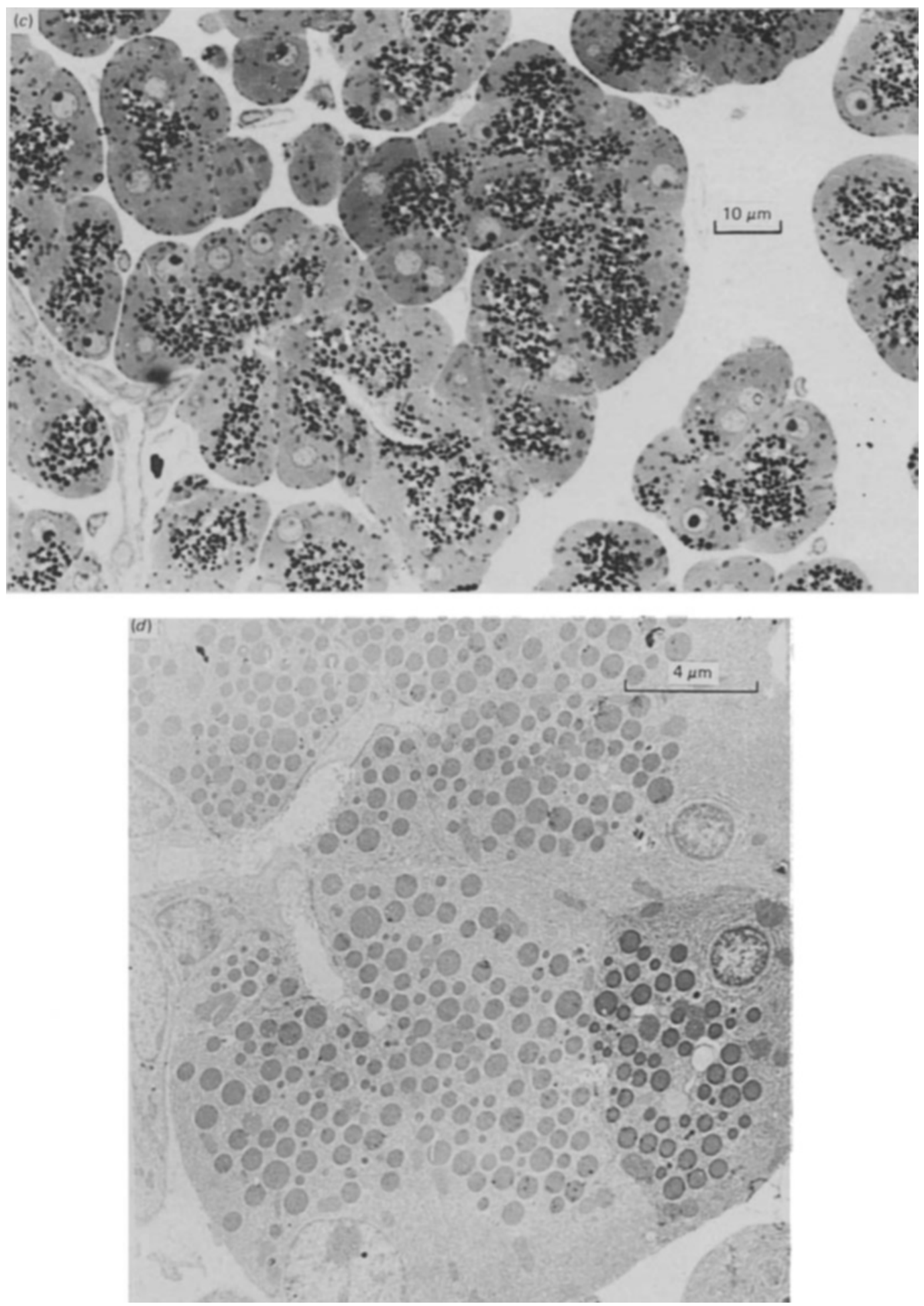